\title{
The Effects of Induction Motor's Steel Sheet Thickness on Efficiency, Losses and Electrical Cost
}

\section{Yanawati Binti Yahya ${ }^{1, *}$, Mohd Khairil Rahmat ${ }^{1}$, Siti Fatihah Salleh ${ }^{2}$, Tuan Ab Rashid Bin Tuan Abdullah ${ }^{2}$}

${ }^{1}$ Universiti Kuala Lumpur (UniKL) British Malaysian Institute (BMI), Batu 8, Jln Sg. Pusu, 53100 Gombak, Selangor, MALAYSIA

${ }^{2}$ Institute of Energy Policy and Research (IEPRe), Universiti Tenaga Nasional (UNITEN), Putrajaya Campus, Jalan IKRAM-UNITEN, 43000 Kajang, Selangor, MALAYSIA

*Corresponding Author

DOI: https://doi.org/10.30880/ijie.2019.11.07.003

Received 30 May 2019; Accepted 30 July 2019; Available online 10 August 2019

\begin{abstract}
Application of the induction motor in industry is common transversely the world. Performance evaluation of its energy efficient was increased the attention as it will convey important energy and commercial funds. This research considered the effects of electrical steel sheet's thickness for rotor material of $0.5 \mathrm{Hp} 3$-phase induction motor on energy efficiency, losses reductions and utility bill cost. The outcome for this research work is thru reducing the lamination thickness of steel sheet (from $0.50 \mathrm{~mm}$ to $0.35 \mathrm{~mm}$ ) for rotor frame, the energy efficiency was increased by $1.4 \%$ and 13.27 Watt of losses have been decreased. Uncertainty the new design is applied to 100,000 pieces a new rotor of motor, it is assessed that $40.32 \mathrm{kWh} /$ year of energy might be saved also the utility bill will be saved up to RM 1.35million.
\end{abstract}

Keywords: induction motor, thickness lamination, energy saving, cost saving, losses reduction, energy efficiency, rotor frame

\section{Introduction}

Energy is the backbone of economic development and imperative part of the $21^{\text {st }}$ century. Globally, energy consumption was expected to increase by $40 \%$ to $50 \%$ in 2010 and global fuel mix is expected to remain substantially the same as today. In the United States (1997), more than 2 billion electric motors were operated, of which around 1.9 billion is fractional horsepower motors, 35 million is direct current (DC) motors and 65 million is induction alternating current (AC) induction motors [1]. Since electric power is generally generated and distributed in AC current form, a converter is needed to convert the AC current to DC current for DC motor application [2]. This will cause some losses and impairment of the current signal. In certain applications such as solar photovoltaic (PV) system, a DC-DC boost converter is required to ensure a high-quality voltage output [3]. In that sense, induction motor is more efficient compared to DC motors.

According to M.Y. Hassan, in terms of energy conservation, the energy can be stored in different ways with different energy industries via machines. Attention of this work is to identify the energy use of major apparatus and apply energysaving opportunities for the equipment via the primary energy. As a major investor of the motor using the whole energy 

industrial, the energy savings through energy-efficient motors have been considered. The formula of annual energy savings (AES) was used when replace the standard motor with higher energy-efficient motor can be predictable [4].

A magnetic field rotating was produced thru stator part (winding), transfers an alternating emf and current in rotor part. Nikola Tesla has created the induction motor in 1888. It involves electrical connections with the rotating part which is the electromagnet was transferred energy beginning at stator part to the rotor (rotating) part of the induction motor. Motor torque will be produced when the secondary interface was induced rotor current at the rotating field of the stator winding. The induction machines signify a classification of rotating field that comprises induction motor, generator, frequency and phase converter and electromagnetic slip coupling [5].

Loss, material type and thickness are the important parameter in designing an induction motor's electrical steel sheet. Loss is defined as; of the induction motor power supply in the system of 3-phase voltage and current. The losses from motor electric such as losses in the stator windings was named the stator copper loss. Then, a total of power loss in hysteresis and eddy current in the material lamination thickness as heat was named core loss. Subsequently the power was transferred to the rotor part, there is a loss was named the rotor loss, and also converted from electrical to mechanical form. In conclusion, the friction and windage and stray loss was subtracted. Staying power is the motor output [6].

In terms of material type, the electrical steel sheet remains commonly used in stator and rotor part for rotating motors. Intended aimed at individuals' requests, there is higher demands for high energy efficiency. Each year, a new lamination steel ranking was developed to present a high in magnetic permeability and low in magnetic loss [7]. This research work was supported by Flat Carbon Europe (2010) which dealt with fully processed electrical steels can separate in two main types of material which are grain-oriented (was used in transformer as shown in Fig. 1) and non-grain oriented (was used in induction motor as shown in Fig. 2). A fundamental difference between two types of material is magnetization direction which is the grain-oriented symbols shows the optimal magnetic behavior in one direction, while the non-grain oriented symbols shows the magnetic properties are isotropic behavioral [8].

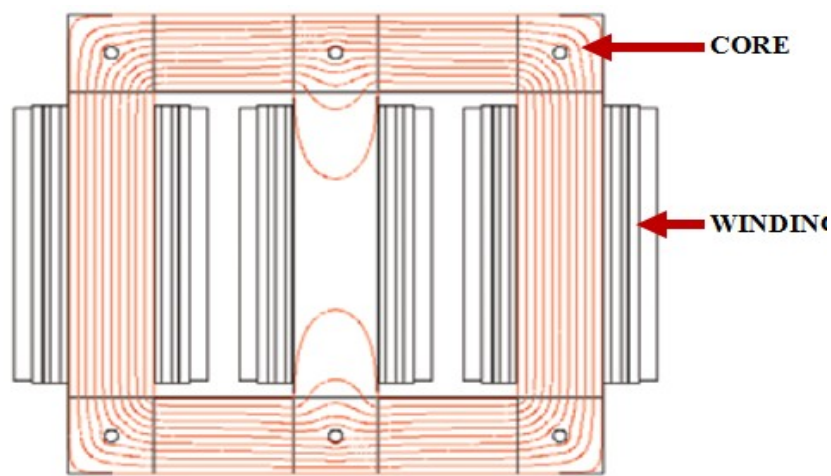

Fig. 1 - Transformer Field Lines [6]

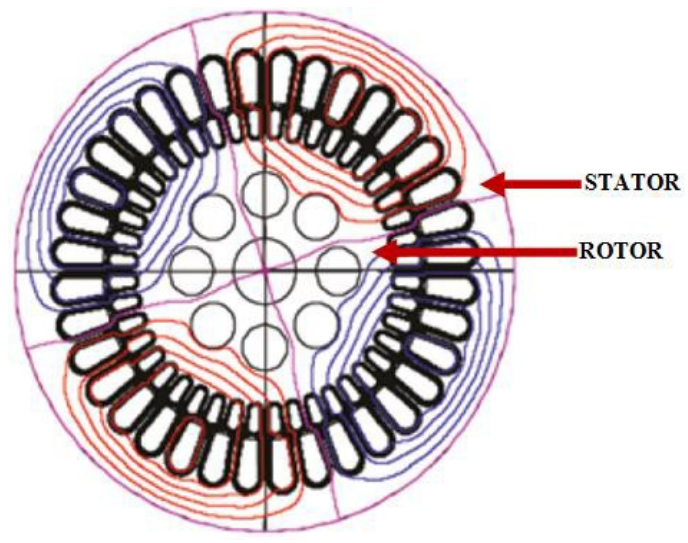

Fig. 2 - Induction Motor Field Lines [6]

Meanwhile, thickness is an important property of electrical steel since it affects the eddy current losses hold, but expensive and tend to decrease the lamination thickness of the vault occupancy declined. A power loss was measured at specified peak operating inductions, aimed at 1.5 Tesla, and this quantity was identified as an active cross-sectional area of metal required. Eddy current was blocked via the laminate. Iron is a good electricity conductivity. The iron core was divided into thin lamination which is the resistance and emf of eddy current was induced in modification to the total power dissipation in the core completely reduce [9].

Yun-Yong Choi mentions that a magnetic property of motor material thru non-oriented silicon steel, commonly used in designing of electrical equipment. The structures of silicon electrical steel were measured via the instruments only and it was dedicated in measuring for each specimen. This is a significant design factor in accomplishing the objectives to improve the efficiency and predict the performance of electrical apparatus. A comparative analysis was conducted regarding to the characteristics of the silicon electrical steel in considering the design of electrical apparatus by referring to the specimen [10].

Katsumi Yamazaki in their research paper work "Calculation of Iron Loss in Rotating Machines by Direct Consideration of Eddy Currents in Electrical Steel Sheets" found that the method used to calculate the iron loss in rotating machineries was proposed. The electromagnetic field distribution and iron loss is numerous types of electrical steel sheets was calculated by the proposed method, formulated as a one-dimensional model. The results are compared with the 
experimental and conventional technique in order to verify the validity of the proposed method. The skin effect and magnetic saturation in an electrical steel sheets on the iron loss characteristics was investigated [11].

Relationship between thickness and efficiency as follows. With substitute the equation, will find as follow:

$$
\eta=\frac{01}{2+03^{2}}
$$

Where ${ }_{1}$ is equal to $P_{O},{ }_{2}$ is equal to $P_{O}$ and ${ }_{3}$ is equal to ${ }^{2} .^{2} .^{2} / 6$. It shows that increasing the thickness lamination of steel sheet will reduce the efficiency of three phase squirrel cage induction motor.

In this paper, the comparison is done in terms of efficiency improvement, losses reductions and economic aspect for $0.35 \mathrm{~mm}$ and $0.50 \mathrm{~mm}$ thickness for induction motor. The electrical steels are used to form the ferromagnetic cores of motors, generators and transformer.

\section{Induction Motor Rotor}

\subsection{Rotor Design}

In designing the rotor part of 3-phase induction motor was prepared via MotorSolve (IM) software. The "round bar" type also diameter bar slot were changed as shown in Fig. 3. The slot pattern was designed in such a way that it consumes a separate 'starting bar' is isolated from the conductor bar main body thru a 'leakage slot' bars, which is relevant to the motor with high conductivity of material in the rotor frame. In addition, a rotor bar slot design has a high in locked rotor torque and slip [12]. The exact diameter size of the original rotor part was measured in order to make sure a new rotor design will fit perfectly into the stator part.

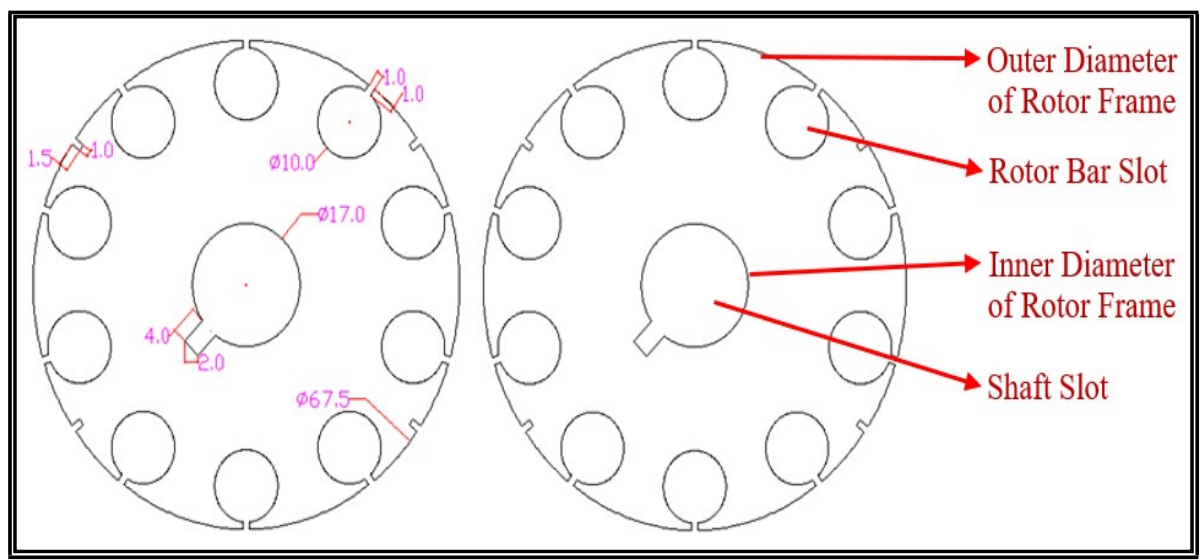

Fig. 3 - Rotor frame design

\subsection{Rotor Frame}

The type of material for rotor frame is M235-35A which is a non-oriented fully processed silicon steel. Normally, a silicon steels was used in rotor frame (also stator frame) in numerous mediums to large size rotating machines, small size power transformer. Some properties in terms of magnetic permeability, electric conductivity, electric permittivity, iron loss, and mass density have been provided in research article. Figure 4 shows that when the flux increases, losses also increase. Losses here are in terms of iron loss, hysteresis loss, and eddy current loss. This type of material is suitable to design the induction motor because it has lower of power loss total [13].

\subsection{Losses Decrement and Efficiency Increment}

Table 1 summarizes the losses on both non-oriented electrical steel sheet thickness which are $0.35 \mathrm{~mm}$ and $0.50 \mathrm{~mm}$ thickness. The simulation software analysis was concluding that $0.35 \mathrm{~mm}$ has better performance. According to the table 
1 below, it shows that the $0.35 \mathrm{~mm}$ consumes definitely decrease the total losses compared to the $0.50 \mathrm{~mm}$ thickness for a rotor frame.

Table 1 - The Material of Rotor Frame Losses Comparison for both thickness

\begin{tabular}{|c|c|c|c|}
\hline \multirow{2}{*}{ Losses Measurement } & \multicolumn{2}{|c|}{ Rotor Frame Thickness (W) } & \multirow{2}{*}{ Energy Saved (W) } \\
\hline & $0.50 \mathrm{~mm}$ & $0.35 \mathrm{~mm}$ & \\
\hline Stator Copper Loss & 8.66 & 6.788 & 1.8 \\
\hline Rotor Loss & 2.652 & 1. & 1.4 \\
\hline Core Loss & 87.1 & $\begin{array}{l}10 \\
79\end{array}$ & 73 \\
\hline Friction \& Windage Loss & 5 & 5 & 0 \\
\hline Stray Loss & 14.23 & $\begin{array}{l}1 \\
2\end{array}$ & $\begin{array}{l}2 . \\
23\end{array}$ \\
\hline Total Loss (W) & 117.64 & 104.37 & $\begin{array}{r}13 . \\
27\end{array}$ \\
\hline Efficiency (\%) & 79.6 & $\begin{array}{l}8 \\
1\end{array}$ & $\begin{array}{l}\text { Approximately Increased }=1.4 \\
0 \%\end{array}$ \\
\hline
\end{tabular}

Fig. 4 demonstrations the separation losses (such as stator copper loss, rotor loss, core loss, friction \& windage loss and stray loss), total loss and efficiency for both thickness (which as $0.35 \mathrm{~mm}$ and $0.50 \mathrm{~mm}$ thickness) with a copper bar. According to the bar graph below, it shows that the $0.35 \mathrm{~mm}$ was reduced the total losses by 13.27 Watt and increase efficiency of $1.4 \%$ compared to the $0.50 \mathrm{~mm}$ thickness. Its show that the $0.35 \mathrm{~mm}$ thickness can increase the efficiency and reduce the copper loss of induction motor.

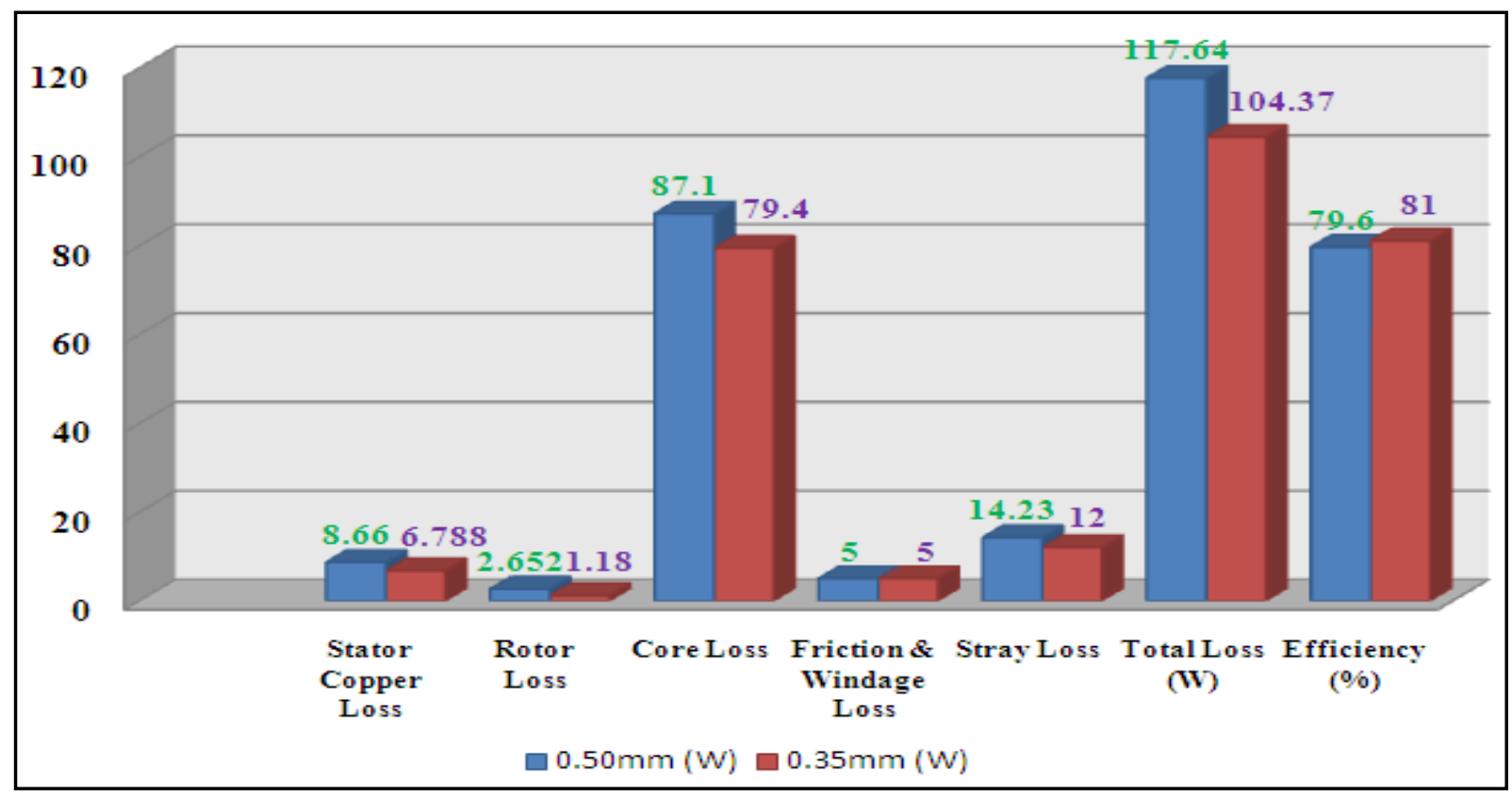

Fig. 4 - The Bar Graph of Separated Losses and Efficiency for Both Thicknesses

Based on Table 1, the efficiency of induction motor using $0.35 \mathrm{~mm}$ has increased nearly to $1.4 \%$ compared to $0.50 \mathrm{~mm}$ thickness. Its shows that the $0.35 \mathrm{~mm}$ thickness was increased the energy efficiency of the motor and will reduces the losses namely stator copper loss and rotor copper loss even though it has a slight increase in the core loss. 


\section{Energy Saving and Economic Benefits}

The energy that can be saved depends on motor size, annual hours of use, efficiency improvement, and the serving utility's charges. The annual energy saving, AES $(\mathrm{kWh})$ was estimated using equation 2:

$$
=h \times \times 0.746 \text { ? } \mathrm{hr} \times\left[^{100} \frac{100}{E}\right] \frac{}{\mathrm{\theta}}
$$

Where;

$$
\begin{array}{ll}
\mathrm{L} & \text { Load Factor } \\
\mathrm{hr} & \text { Yearly Operating Hour } \\
\mathrm{E}_{\mathrm{std}} & \text { Efficiency of } 0.50 \mathrm{~mm} \text { thickness } \\
\mathrm{E}_{\mathrm{cr}} & \text { Efficiency of } 0.35 \mathrm{~mm} \text { thickness }
\end{array}
$$

The annual bill savings $\left(\mathrm{kWh}_{\text {savings }}\right)$ was attained thru multiplying the operating hours number with specified load was used equation 3 below:

Where

$$
\text { ? } h_{\text {回 回 } i g}=\times h r
$$

? $h_{a \text { 回 } g} \Rightarrow$ the expected annual bill savings (RM)

AES $\Rightarrow$ the annual energy savings

$h r \Rightarrow 24 \times 336$ working days.

Total cost savings (TCS) can be explained through equation 4 below:

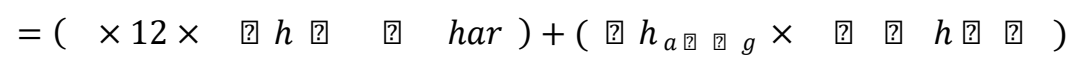

The load factor and running time were assumed to be $100 \%$ and $8,064 \mathrm{hr}$ respectively. Table 2 shows the results of efficiency, loses, and energy saving for both thicknesses.

Table 2 - The Comparison of Energy and Total Amount Saving for Both Thickness

\begin{tabular}{ccc}
\hline & $\mathbf{0 . 5 0} \mathbf{~ m m}$ & $\mathbf{0 . 3 5} \mathbf{~ m m}$ \\
\hline $\begin{array}{c}\text { Energy Saving (W) } \\
\text { Annual Energy Saving (AES) } \\
\mathbf{( 8 , 0 6 4} \text { Hours / year) }\end{array}$ & 1 & 5 \\
Total Cost Saving (TCS) & $8.06 \mathrm{kWh}$ & $40.32 \mathrm{kWh}$ \\
Monthly Demand Charge & $\mathrm{RM} 2.71$ & $\mathrm{RM} 13.54$ \\
Monthly Energy Charge & $\mathrm{RM} 7.20$ & $\mathrm{RM} 7.20$ \\
(Tariff D) & $32.5 \mathrm{sen} / \mathrm{kWh}$ & $32.5 \mathrm{sen} / \mathrm{kWh}$ \\
Saving for 100, 000 motors & $\mathrm{RM} \mathrm{271,000.00}$ & $\mathrm{RM} 1,354,000.00$ \\
\hline
\end{tabular}

The total amount of energy was preserved thru the copper rotor bar for induction motor throughout each hour of use $40.32 \mathrm{kWh} /$ year. The total cost saving per copper rotor motor when using $0.35 \mathrm{~mm}$ thickness compared to $0.50 \mathrm{~mm}$ is $\mathrm{RM}$ 13.54. Assuming this design was applied to 100,000 pieces of motor, 1.35 million of electricity cost could be saved.

\section{Conclusion}

Rotor frames of $0.35 \mathrm{~mm}$ and $0.50 \mathrm{~mm}$ thickness were fabricated and tested. Based on MotorSolve's simulation and analysis, we found that the rotor with $0.35 \mathrm{~mm}$ thickness could reduce the total loss and the annual energy by 40.32 
$\mathrm{kWh} /$ year/motor. Meanwhile, in terms of the total cost saving, the usage of rotor frame of $0.35 \mathrm{~mm}$ thickness would offer higher utility bill saving by RM 13.54/year/motor compared to rotor frame of $0.50 \mathrm{~mm}$ thickness which offers RM 2.71 . Assuming that 100,000 was used, the total potential saving is up to RM 1.35 million a year.

\section{Acknowledgement}

The authors wish to thank the Director \& members of Center for Research \& Innovation (CoRI), Universiti Kuala Lumpur (UniKL) and the Director \& members of Institute of Energy Policy and Research (IEPRe), The National Energy University (UNITEN), for the technical and financial support and also to Infolytica for the Motorsolve (IM) software.

\section{References}

[1] Chapman, S. J. (2005). Electric Machinery Fundamentals (4 ${ }^{\text {th }}$ ed.): Mc Graw Hill.

[2] Mohammed, K.G., Ramli, A. Q., Ungku Amirulddin, U. A. (2012). A New Design of Six-Phase Rotary Converter Electric Machine. International Journal of Integrated Engineering, 3(4), 48-53.

[3] Kasiran, A. N., Ponniran, A., Ngamidun, N. A. S., Shaili, M. S., Zaini, A. M., Yatim, M. H. (2019). Optimum Phase Selection of Multiphase Interleaved DC-DC Boost Converter for Current Stress and Switching Devices Losses Reduction. International Journal of Integrated Engineering, 1(11), 11-18.

[4] Hassan, M.Y., Majid, M.S., \& Rahman, H.A. (2000). Application of energy efficient motor in Malaysian industries. IEEE Region 10 Annual International Conference, Proceedings/TENCON 2000, 2, 97-102.

[5] Chaudhari, S. (2004). Load based energy savings in three phase squirrel cage induction motors (Masters dissertation, West Virginia University, 2004). Department of Industrial and Management Systems Engineering, Morgantown.

[6] Theodore, W., (2006). Electrical machines, drives and power systems (6th ed). New Jersey: Pearson Prentice Hall.

[7] Landgraf, F. J. G., Emura, M., Ito, K., \& Carvalho, P. S. G. (2000). Effect of plastic deformation on the magnetic properties of non-oriented electrical steels. Journal of Magnetism and Magnetic Materials,2000, 215-216.

[8] Flat Carbon Europe. (2010). Non-Oriented Fully Processed Electrical Steels. ArcelorMittal, (L).

[9] Backley, P. (2002). Electrical Steels for rotating machines (IEE power and energy series; no. 37): The Institution of Electrical Engineers, London, United Kingdom.

[10] Yun-Yong, C., Jun-Woo, C., \& Jung-Pyo, H. (2016). The Magnetic Properties of Electrical Steel for Rotating Machine according to the Specimen. Journal of Magnetics, 21(2), 209-214

[11] Katsumi, Y., Makoto, T., Hitoshi, S. (2011). Calculation of Iron Loss in Rotating Machines by Direct Consideration of Eddy Currents in Electrical Steel Sheets. Electrical Engineering in Japan, Vol. 176, No. 3, 2011, Translated from Denki Gakkai Ronbunshi, Vol. 128-D, No. 11, November 2008, pp. 1298-1307

[12] Yanawati, Y., Daut, I., Nor Shafiqin, S., Pungut, I., Syatirah, M. N., Gomesh, N., Siti Rafidah, A. R., Haidar, N. (2012) Efficiency Increment on $0.35 \mathrm{~mm}$ and $0.50 \mathrm{~mm}$ Thicknesses of Non-oriented Steel Sheets for $0.5 \mathrm{Hp}$ Induction Motor. International Journal of Materials Engineering, 2(2), 1-5

[13] MotorSolve. (2015). M235-35A. infolytica. Retrieved from info@infolytica.com 